\title{
Colonic ulcerations associated with diclofenac treatment
}

\author{
BERND SCHÖNBERGER, CAND MED, STEPHAN NICKL, CAND MED, \\ FRANZJOSEF SCHWEIGER, BSC, MD, FRCPC, FACG
}

B SCHÖNBERGER, S NICKL, F SCHWEIGER. Colonic ulcerations associated with diclofenac treatment. Can J Gastroenterol 1992;6(1):15-17. Nonsteroidal anti-inflammatory drugs frequently exert toxic effects on the upper gastrointestinal mucosa. However, inflammation and ulcerations in the colon secondary to these agents have been increasingly recognized in recent years. A patient presenting with abdominal pain, weight loss and diarrhea while taking a slow release form of diclofenac sodium (Voltaren SR; Ciba-Geigy) is described. Extensive ulcerations in the right colon and healing upon discontinuation of the drug are documented by colonoscopy.

Key Words: Colonic ulceration, Diclofenac sodium

\section{Ulcérations coliques associées au traitement par diclofénac}

RESUME: Les anti-inflammatoires non stéroïdiens (AINS) ont souvent des effets nocifs sur la muqueuse gastrointestinale supérieure. Depuis ces dernières années, on reconnaît aussi de plus en plus fréquemment qu'ils provoquent l'inflammation et l'ulcération du côlon. On rapporte le cas d'un patient traité par du sodium de diclofénac à libération lente (Voltaren SR; Ciba-Geigy) et qui s'est plaint de douleurs abdominales, d'une perte pondérale et de diarrhée. Les ulcérations étendues du côlon droit et la guérison à l'arrêt du traitement ont été constatées sous colonoscopie.

Tech University of Munich, Munich, Germany; and The Moncton Hospital, Moncton, New Brunswick

Correspondence and reprints: Dr F Schweiger, 100 Arden Street, Suite 405, Moncton, New Brunswick ElC 4B7. Telephome (506) 858-8441

Received for publication October 25, 1991. Accepted December 11, 1991
$\mathrm{N}^{\circ}$ ONSTEROIDAL ANTI-INFLAMMAtory drugs (NSAIDs) are frequently prescribed medications with widely known adverse effects on the upper gastrointestinal mucosa. In recent years evidence has accumulated that NSAIDs are also potentially toxic to the lower intestinal tract and that chronic use may lead to small intestinal inflammation in a large number of patients (1). It appears that colonic injury caused by NSAIDs may account for a significant number of cases of newly diagnosed colitis (2).

The authors describe the occurrence of colonic ulceration in a patient caused by a slow release preparation of diclofenac sodium (Voltaren SR; CibaGeigy).

\section{CASE HISTORY}

A 73-year-old male initially presented with a 'flu-like illness and increasing arthralgias while on vacation. He was prescribed diclofenac sodium (Voltaren SR; Ciba-Geigy) at a dose of $75 \mathrm{mg}$ 


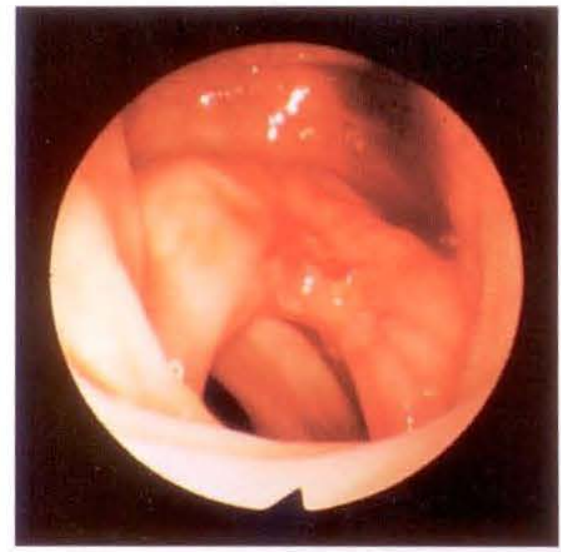

Figure 1) Colonoscopy showing a circular ulcer at the ileocecal valve

twice a day. Shortly thereafter he developed constipation and recurrent postprandial vomiting which persisted for approximately one month. At that point he noticed increasingly lower abdominal cramps and loose to watery, nonbloody bowel movements as well as nocturnal diarrhea. This was associated with generalized weakness and a $2.3 \mathrm{~kg}$ weight loss. Hemoglobin level dropped from $122 \mathrm{~g} / \mathrm{L}$ to $108 \mathrm{~g} / \mathrm{L}$ and white blood cell count rose from 10.6 to 17.3 $\times 10 \mathrm{~g} / \mathrm{L}$ (12\% band forms). Three consecutive stool samples were positive for occult blood.

The patient had no previous gastrointestinal complaints and he reported always having had regular bowel habits. Past medical history included mild hypertension, pacemaker dependency and stable angina pectoris for which he was taking atenolol and nitroglycerin. There was no recent change or deterioration of cardiovascular status.

Physical examination revealed a normotensive afebrile male. There were no signs of heart failure. The abdomen was slightly distended and tender in both lower quadrants. Apart from diffuse osteoarthritic changes in the extremities and a pacemaker in the left upper chest, the examination was unremarkable.

A barium enema showed small sigmoid diverticula. An upper gastrointestinal series and small bowel barium study was normal with good visualization of the terminal ileum.

A colonoscopy revealed two partially digested pills in the cecal tip as well

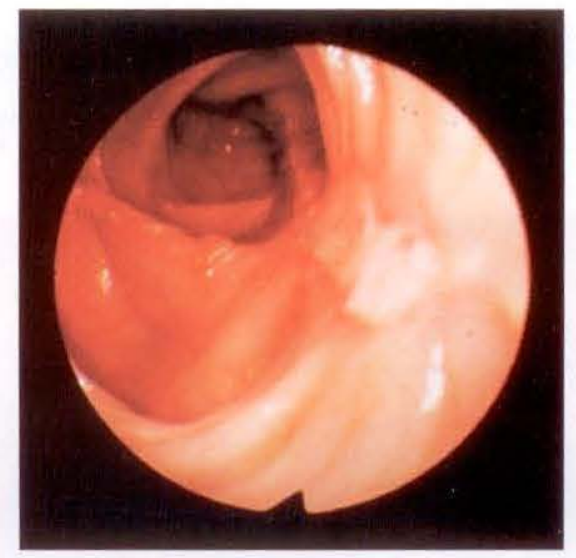

Figure 2) Endoscopic view of linear ulceration near the hepatic flexure

as erythema and a small area of ulceration just proximal to the ileocecal valve (Figure 1). However, there was extensive linear ulceration at the hepatic flexure extending for almost $10 \mathrm{~cm}$ into the proximal transverse colon (Figure 2 ). The surrounding mucosa was normal in appearance as was the distal colon. Biopsies obtained from the ulcers showed inflammatory infiltration and granulation tissue with no evidence of granulomas.

Diclofenac sodium was discontinued and the patient was started on 5 aminosalicylic acid (Asacol; Norwich Eaton) tid $800 \mathrm{mg}$. Symptoms improved and disappeared after approximately two weeks; he stopped taking Asacol two months later. A repeat colonoscopy six months later was normal except for an obvious scar at the previous site of ulceration near the hepatic flexure (Figure 3). Hemoglobin was 139 $\mathrm{g} / \mathrm{L}$. The patient has remained asymptomatic after one year of follow-up.

\section{DISCUSSION}

The association between NSAIDs and lower gastrointestinal inflammation is well described in the literature and was reviewed recently (3).

The administration of these agents to patients with known quiescent idiopathic inflammatory bowel disease may provoke a relapse (4). De novo colonic injury induced by NSAIDs may range from nonspecific colitis or proctitis to ulceration and the associated complications of perforation, bleeding, stricture formation and even fistulization (3). A

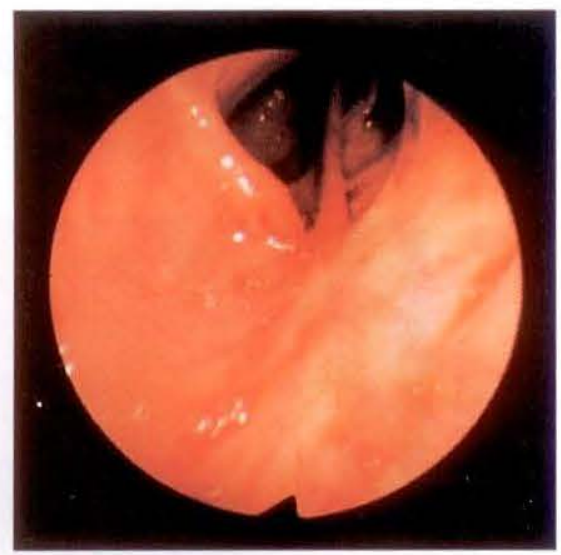

Figure 3) Endoscopic view of residual scar caused by the ulceration shown in Figure 2 six months after discontinuation of diclofenac

severe necrotizing enterocolitis has been reported in infants given indomethacin as treatment for a persistent patent ductus arteriosus (5).

In most cases described in the literature causal relationship between an NSAID and colitis is supported by epidemiological data (6), a temporal association or by reproducing colonic injury by rechallenge with the NSAID (7). In addition, animal models of NSAIDinduced intestinal ulceration (8) and human volunteer studies showing ileocecal inflammation by indium-labelled leukocytes after NSAIDs support the existence of this pathological entity (9).

The clinical course of the present patient, the lack of predisposing factors except for diclofenac, and the colonoscopic finding of medication in the vicinity of the ulcerated mucosa are in keeping with NSAID-induced colitis. The authors could not identify the pills with certainty as Voltaren SR but their presence in the cecum suggests relative stasis in this part of the colon facilitating prolonged direct contact between the mucosa and the injurious agent.

Voltaren SR is a slow release preparation of diclofenac sodium, an NSAID that is widely prescribed and has potent anti-inflammatory properties. According to Willkens (10) who reviewed the worldwide clinical safety experience, diclofenac is one of the safest agents of its kind in the treatment of a broad range of rheumatic conditions. However, in recent years there have been several reports suggesting potential toxicity of this drug towards ileal and 
colonic mucosa $(11,12)$. Ileal perforation has been reported after excessive and therapeutic doses $(13,14)$.

The first well documented cases of colonic ulceration in the English literature were reported by Carson and colleagues in 1990 (15). These authors described two female patients who presented with positive stool tests for occult blood and anemia. However, as both patients took other potentially colonotoxic drugs the causal association between Voltaren SR and colonic injury has been questioned (16). Witham (14) reported two further patients taking Voltaren who developed abrupt bleeding secondary to proximal colonic ulceration (14). Most

\section{REFERENCES}

1. Bjarnason I, Zanelli G, Smith T, et al Nonsteroidal antiinflammatory druginduced intestinal inflammation in humans. Gastroenterology 1987;93:480-9.

2. Tanner AR, Raghunath AS. Colonic inflammation and nonsteroidal antiinflammatory drug administration. Digestion 1988;41:116-20.

3. Aabakken L, Osnes M. Non-steroidal anti-inflammatory drug-induced disease in the distal ileum and large bowel. Scand J Gastroenterol $1989 ; 24: 48-55$.

4. Kaufmann HJ, Taubin HL. Nonsteroidal anti-inflammatory drugs activate quiescent inflammatory bowel disease. Ann Intern Med 1987;107:513-6.

5. Nagaraj HS, Sandhu AS, Cook LN, Buchino JJ, Groff DB. Gastrointestinal perforation following indomethacin therapy in very low birth weight infants. ] Pediatr Surg 1981;16:1003-7.

6. Langman MJS, Morgan L, Worrall A. Use of anti-inflammatory drugs by patients admitted with small or large recently, diaphragm-like thin colonic strictures secondary to slow release diclofenac therapy have been described in a patient who two years earlier was found to have right-sided colonic ulcerations while taking the drug (17).

The mechanism of NSAID-induced colonic injury remains elusive. Interference with prostaglandin production and/or diversion of the arachidonic pathway towards the lipooxygenase cascade resulting in the generation of harmful leukotrienes and free radicals are prime candidate mechanisms (18). These alterations may lead to increased mucosal permeability permitting luminal antigens to gain better access to the immune system (9). A possibly

howel perforations and hemorrhage. Br Med J 1985;290:347-9.

7. Ravi S, Keat AC, Keat ECB. Colit is caused by nonsteroidal antiinflammatory drugs. Postgrad Med ] 1986;62:773-6.

8. Bjarnason I, Smethurst P, Levi AJ, Price AB. Indomethacin induced chronic small intestinal ulceration in the rat. Gastroenterology 1988;94:A37.

9. Bjarnason I, Williams P, So A, et al. Intestinal permeability and inflammation in rheumatoid arthritis: Effects of non-steroidal antiinflammatory drugs. Lancet 1984;ii:1171.

10. Willkens RF. Worldwide clinical safety experience with diclofenac. Semin Arthritis Rheum 1985;15:105-10.

11. Güller R. Die Nebenwirkungen nicht-steroidaler Antirheumatika im unteren Gastrointestinaltrakt. Schweiz Med Wschr 1987;117:1527-33.

12. Ritschard T, Filippini L. Side effects of non-steroidal antirheumatics on the lower intestinal tract. Dtsch Med Wochenschr 1986;111:1561-4.

13. Deakin M. Small bowel perforation associated with an excessive dose of local toxic effect is supported by previous case reports $(17,19)$, by studies showing direct rectal injury from NSAIDs in suppository form (20), and by the present case report describing proximal colonic ulceration induced by diclofenac in slow-release form.

NSAID-associated colitis is an important entity to consider in any patient presenting with the clinical picture of inflammatory bowel disease. Diclofenac sodium-associated colonic toxicity may manifest itself as asymptomatic blood loss, acute lower gastrointestinal bleeding or nonbloody diarrhea, abdominal pain and weight loss. The diagnosis is best established by colonoscopic examination.

slow release diclofenac sodium. Br Med J 1988;297:488-9.

14. Witham R. Voltaren (diclofenac sodium)-induced ileocolitis. Am J Gastroenterol 1991;86:246-7.

15. Carson J, Notis WM, Orris ES. Colonic ulceration and bleeding during diclofenac therapy. $\mathrm{N}$ Engl J Med 1990;323:135. (Lett)

16. Bernstein J. Colonic ulceration and bleeding during diclofenac therapy. N Engl J Med 1990;323:135. (Lett)

17. Huber T, Ruchti C, Halter F. Nonsteroidal anti-inflammatory drug-induced colonic strictures: A case report. Gastroenterology 1991;100:1119-22.

18. Bjarnason I, MacPherson A. The changing gastrointestinal side effect profile of non-steroidal antiinflammatory drugs. Scand ] Gastroenterol 1989;24:56-64.

19. Day TK. Intestinal perforation associated with osmotic slow-release indomethacin capsules. Br Med J 1983;287:1671-2.

20. Levy N, Gaspar E. Rectal bleeding and indomethacin suppositories. Lancet $1975 ; 1: 577$. 


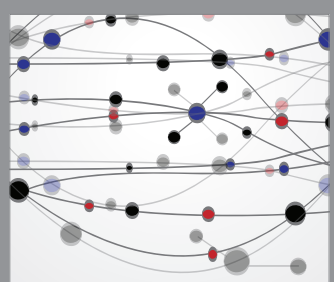

The Scientific World Journal
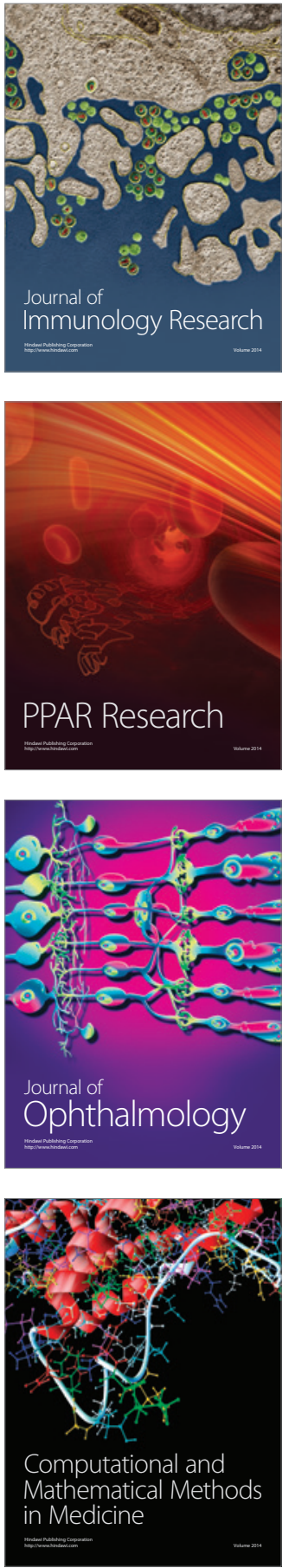

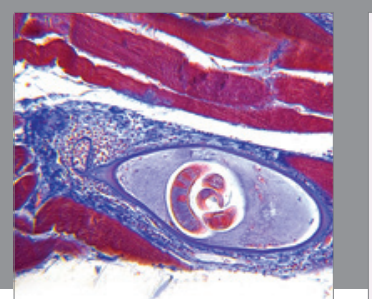

Gastroenterology Research and Practice

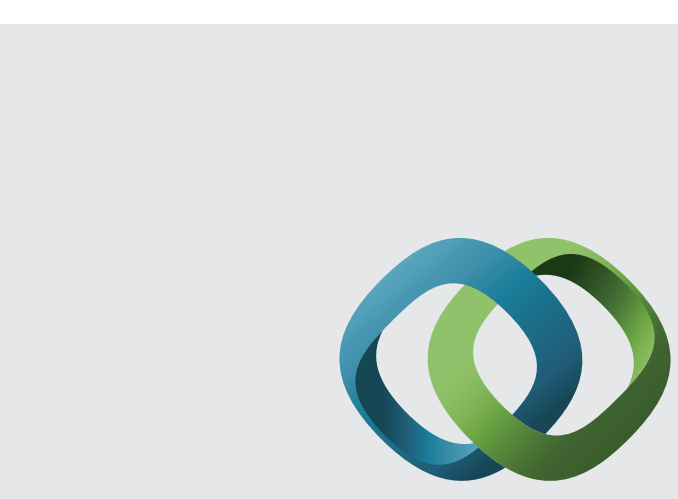

\section{Hindawi}

Submit your manuscripts at

http://www.hindawi.com
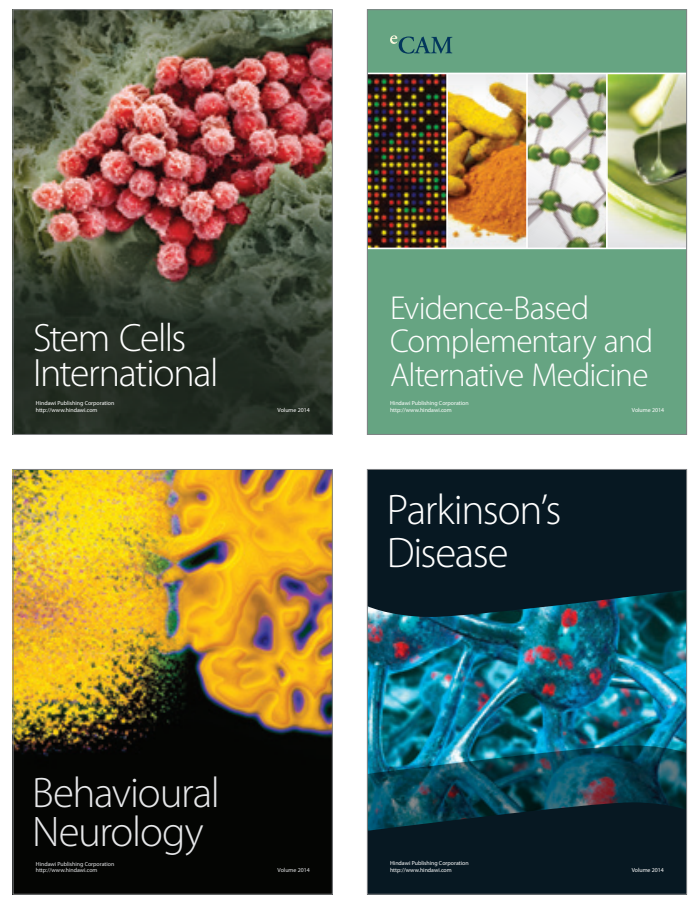
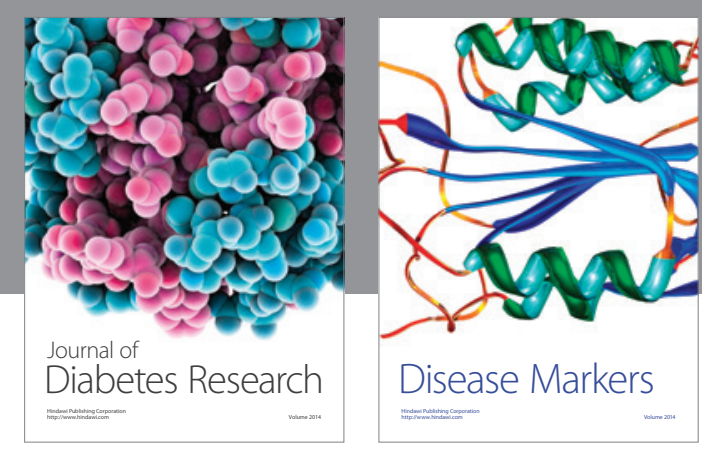

Disease Markers
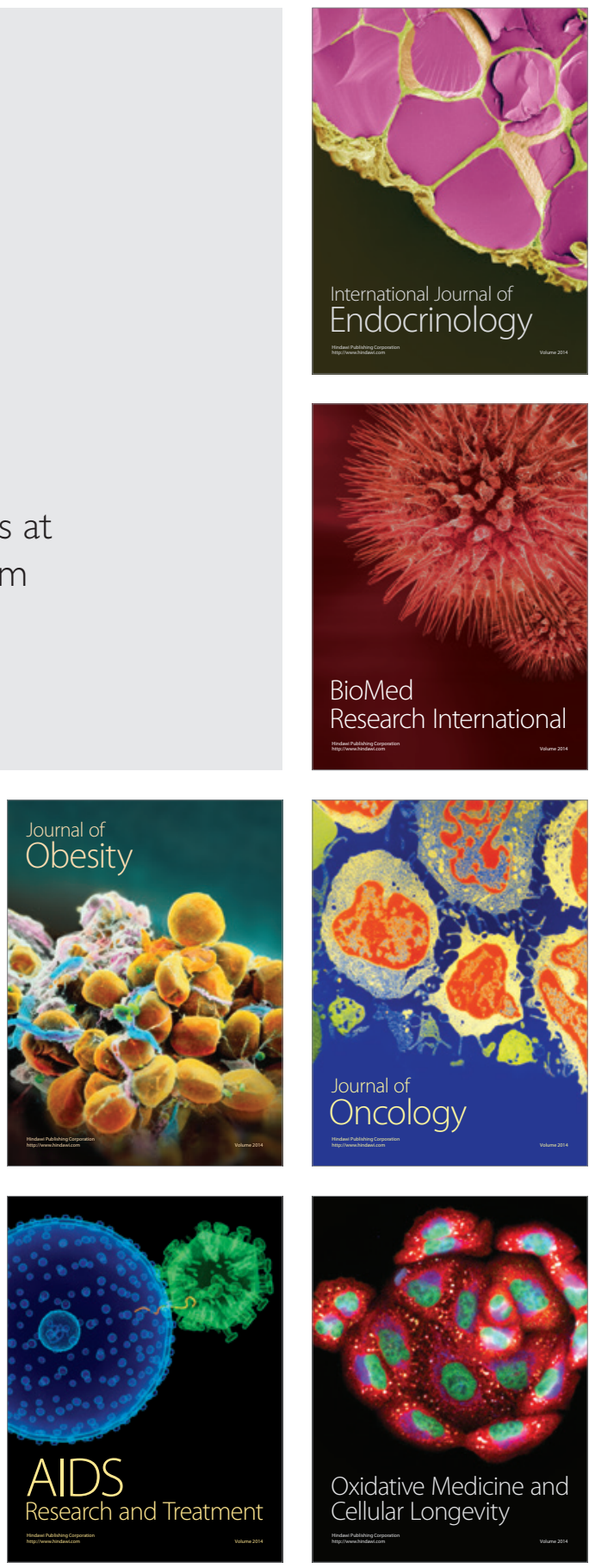